\title{
Development of fiber enriched herbal biscuits: A preliminary study on sensory evaluation and chemical composition
}

\author{
Md. Ariful Alam ${ }^{1, ~ *, ~ M d . ~ J a h a n g i r ~ A l a m ², ~ M d . ~ A b d u l ~ H a k i m ³ ~, ~ A . ~ K . ~ O b i d u l ~ H u q ², ~}$ \\ S. M. Golam Moktadir ${ }^{2}$ \\ ${ }^{1}$ Department of Food Technology, Thakurgaon Polytechnic Institute, Thakurgaon 5100, Bangladesh \\ ${ }^{2}$ Department of Food Technology and Nutritional Science, Mawlana Bhashani Science and Technology University, Santosh, Tangail- \\ 1902, Bangladesh \\ ${ }^{3}$ Department of Agricultural Chemistry, Hajee Mohammad Danesh Science \& Technology University, Dinajpur 5200, Bangladesh
}

\section{Email address:}

arifuliuanft@yahoo.com (M. A. Alam), ahakimupm@.gmail.com (M. A. Hakim)

\section{To cite this article:}

Md. Ariful Alam, Md. Jahangir Alam, Md. Abdul Hakim, A. K. Obidul Huq, S. M. Golam Moktadir. Development of Fiber Enriched Herbal Biscuits: A Preliminary Study on Sensory Evaluation and chemical Composition. International Journal of Nutrition and Food Sciences. Vol. 3, No. 4, 2014, pp. 246-250. doi: 10.11648/j.ijnfs.20140304.13

\begin{abstract}
The study was designed to formulate a fiber enriched herbal biscuits (Holy Basil and Moringa) that contains sufficient nutrient (protein and fiber enriched). The objectives of this research were to determine the Biochemical and organoleptic attributes of Herbal biscuit substituted with four different percentages i.e., Normal, Sample -1(1\%), Sample $2(2 \%)$ and Sample - $3(3 \%)$ both Tulshi and Moringa leaves. Fiber enriched herbal biscuits were developed by incorporating Tulshi (Ocimum sanctum) leaves, Moringa (Moringa oleifera) leaves, whole wheat flour, egg white, vegetable oil, margarine (dalda) and other necessary ingredients. This recipe was standardized and evaluated for organoleptic acceptability by five point's hedonic scale. The overall acceptability score of normal biscuit, sample biscuit 1 , 2 and 3 were 4.46, 4.43, 4.03 and 4.14 respectively out of 5 . The nutritive values of the normal standard biscuits were protein $14.7 \mathrm{~g}$, fat $19.5 \mathrm{~g}$, carbohydrate $56.6 \mathrm{~g}$, fiber $2.3 \mathrm{~g}$, ash $2.1 \%$ and $458 \mathrm{Kcal}$. On the other hand, the prepared herbal biscuits of sample-1 contain $4.6 \%$ moisture, $2.9 \%$ crude fiber, $460 \mathrm{Kcal}$ energy and $14.8 \%$ protein, $20.1 \%$ fat, $55.4 \%$ carbohydrate, $2.2 \%$ ash. But the Sample-2 and 3 biscuits contains $4.5 \%$ moisture, 3.5\% crude fiber, 457 Kcal energy and $14.6 \%$ protein, $19.9 \%$ fat, $55.2 \%$ carbohydrate, $2.3 \%$ ash and $4.7 \%$ moisture, $4.1 \%$ crude fiber, 449 Kcal energy and $14.9 \%$ protein, $19.3 \%$ fat, $54.6 \%$ carbohydrate, $2.4 \%$ ash respectively. It was noted that the quality characteristics were improved due to incorporation of acceptable level of Tulshi and Moringa leaves at certain proportion. The organoleptic test showed that the addition of both Tulshi and Moringa leaves at 1\% was more acceptable comparing with all quality characteristics.
\end{abstract}

Keywords: Herbal Biscuit, Holy Basil, Moringa, Dietary Fiber, Protein, Carbohydrate, Fat, Organoleptic Test, Nutritive Value, Hedonic Scale

\section{Introduction}

Dietary fiber is the endogenous components of plant material in the diet which are resistant to digestive enzymes produced by man. Dietary fiber is an important part of a healthy diet. It helps move food and waste efficiently through the digestive system [1]. Fiber is the part of plant foods that cannot be broken down by human digestive enzymes in the small intestine [2]. Fiber is mostly complex carbohydrates. The two types of fiber are soluble and insoluble. While they work differently, both are needed for proper bowel function. Most fiber sources contain both kinds of fiber in varying amounts. Insoluble Fiber cannot be dissolved in water. This type of fiber attracts water to the intestines, making stools bulky and soft. It also speeds the movement of food through the digestive tract. Therefore, insoluble fiber may help prevent diverticular disease, colon cancer, hemorrhoids, and constipation. Cellulose, hemi cellulose and lignin are insoluble fibers. They produce the tough, chewy texture of wheat bran, whole grains, corn bran, and some vegetables [3]. Soluble fiber, or fiber that can dissolve in water, slows the movement of food through 
the body but does not increase fecal bulk. Soluble fiber helps maintain a healthy cholesterol level, normalize blood sugar levels in diabetics and may even help reduce blood pressure. Pectins and gums are examples of soluble fibers, and they are also found in herbs like Tulshi (Ocimum sanctum), Moringa Leaves (Moringa oleifera), beans, oat bran, psyllium husks, Apple, Apricot, Carrots, Yams and some fruits and vegetables[4,5].

Dietary fiber is essentially intact within the plant matrix, and the enzymes within the human digestive tract are unable to hydrolyze or break it down. Dietary fiber is made up of three varying components. The largest component consists of polysaccharides, or plant fibers such as bran; pectins from fruits and vegetables; various gums; and betaglucans from oats and rye [5]. The second-largest component is lignin, composed of polyphenylpropane molecules and present in very small amounts in the diet. Lignin is found in stalks and stems. The final component is made up of resistant starches and non-digestible oligosaccharides [6]. These are naturally occurring parts of fiber that resist digestion in the upper digestive tract yet feed and stimulate the growth of friendly bacteria in the lower digestive tract. Resistant starches and oligosaccharides are sometimes added to food as isolated ingredients (e.g., polydextrose) and occur naturally in legumes, various fruits and vegetables, seeds and grains [5]

Many observational studies have found an association between high-fiber food consumption and reduced risk of type II diabetes. Dietary fiber is thought to play a vital role in reducing overall risk by helping to normalize postprandial glucose response and decrease insulin concentration and overall insulin requirements. Higher intakes (13-16 g/dy in one study and as much as 30-50 $\mathrm{g} /$ dy in a different study) from whole-food sources in particular, cereal fiber-have been consistently associated with lower risk of type II diabetes and improved insulin sensitivity[7].

The American Dietetic Association states that 30 to 50 $\mathrm{g} /$ day of fiber from whole food sources consistently assists in lowering blood glucose concentrations [8]. Dietary fiber has been shown to improve insulin sensitivity in individuals with type II diabetes [9]

The suggested benefits of increased intake of fiber include not only the reduction in postprandial rise in blood glucose concentration but also lower basal glucose concentration, enhanced sensitivity to insulin, and lower cholesterol level. The soluble fibers, e.g., guar and pectin, increase intestinal transit time [4]. Whereas the insoluble fibers such as wheat bran and whole grain decrease the intestinal transit time and increase intestinal bulk. Studies with D-xylose have shown that the glucose-lowering effects may be a consequence of decreased rate of carbohydrate absorption rather than increased total glucose utilization or suppression of hepatic glucose production [3]. The possible effects of fiber within the small intestine include changes in mixing, motility, and convection; intraluminal digestion rates; thickness of the unstirred layer; inhibition of maximum transport capacity; altered $\mathrm{pH}$ profile; and, with long-term treatment, altered intestinal morphology [10].

Dietary fiber is considered as an important and essential component of diet and fiber obtained from various sources has been successfully incorporated in the food products with significant results. In recent years several types of breakfast cereals containing high amount of bran has been developed and marketed as it helps in weight control and play a key role in reducing colon cancer. Enhancement of fiber content in snack foods, beverages, spices, sauces, frozen foods, meat products and other foods has also been investigated. Health benefits of dietary fiber indicate that dietary fiber may give protection against cardiovascular diseases, diabetes and obesity [11].

There are many sources of dietary fiber such as fruits, vegetables and less commonly used cereals such as barley, which are potential sources of dietary fiber supplements and herbs like Tulshi (Ocimum sanctum) and Moringa (Moringa oleifera).

Ocimum sanctum traditionally used since the times of ancient civilization in Bangladesh and called as the "Queen of Herbs". The unique chemistry of Tulsi is highly complex. Tulsi contains hundreds of beneficial compounds known as phyto-chemicals. Working together, these compounds possess strong antioxidant, antibacterial, antiviral, adaptogenic, and immune enhancing properties that promote general health and support the body's natural defense against stress and diseases [12]. It contains $7.0 \%$ eugenol, carvacrol (3\%) and eugenol-methyl ether (20\%). It also contains caryophyllin, ursolic acid, rosmaric acid, thymol, methyl chavicol, citral, carvacrol, $\beta$-caryophyllene. It has been observed that eugenol and the essential oils possessed membrane stabilizing properties on synaptosomes, erythrocytes and the mast cells which account for the therapeutic potentials of Tulsi in management of neurological, inflammatory and allergic disorders. It was also pharmacologically evaluated and found to reduce raised blood sugar, cholesterol and triglyceride levels and activities of GPT, GOT, LDH and alkaline phosphatase in blood serum and thereby it is therapeutically used as cardioprotective, antidiabetic, hepatoprotective and hypolipidemic agent [13].

Modern scientific research offers impressive evidence that Tulsi reduces stress, enhances stamina, relieves inflammation, lowers cholesterol, eliminates toxins, protects against radiation, prevents gastric ulcers, lowers fevers, improves digestion and provides a rich supply of antioxidants and other nutrients. Tulsi is especially effective in supporting the heart, blood vessels, liver and lungs and also regulates blood pressure and blood sugar [12].

Moringa (Moringa spp.) belongs to a monogenetic family, the Moringaceae. Moringa oleifera is also known as "Miracle Tree". Moringa oleifera has a host of other country specific vernacular names, an indication of the significance of the tree around the world. It is a small fastgrowing ornamental tree originally belongs to India. Various varieties of Moringa oleifera have been developed 
to meet the tastes of local populations. Cited as one of the world's most useful plants, Moringa leaves are edible and are of high nutritive value. It is consumed throughout Asian countries. It is a cosmopolitan tropical drought tolerant tree, available throughout the year and is documented in eastern allopathic medicine to possess various pharmacological actions, such as analgesic, antihypertensive activity, and anti-inflammatory effects $[14,15,16]$.

A study evaluates the effects on taking tea prepared from Moringa oleifera Lam. on blood sugar levels in humans. The results point to the benefit of using Moringa oleifera Lam. tea in the management of hyperglycemia [17].

Biscuits are ideal for their nutritive value, palatability, compactness and convenience [18]. Having low moisture content than cakes and bread, biscuits are generally safer from microbiological spoilage and have long shelf-life [19]. The present investigation was planned to develop a product with high fiber content and low caloric value.

Biscuits have always been one of the most popular and appealing food products due to its superior nutritional, sensorial and textural characteristics, ready to eat convenience as well as cost competitiveness [20]. Nowadays, emphasis is on healthy Biscuits with low glycemic index, more protein and will increase the dietary fiber intake, high resistant starch and decrease in calorie and carbohydrates of baked goods. Herbal Biscuits are made by incorporation of Tulshi and Moringa leaves in a mixture of whole wheat flour, wheat flours, sugar powder, vegetable oil (soybean), dalda, baking powder, skim milk powder, egg white, iodized salt, and other general ingredients.

All these ingredients will impart characteristic colors, texture and nutritional value which may be favorable in bakery products, recipes and other food products. The composite flours are advantages to the developing countries because the flour could reduce wheat imports and increased the potential use of locally grown crop.

\section{Materials and Methods}

\subsection{Place of Experiment}

The samples analyses were conducted in the laboratory of Food Technology and Nutritional Science Department, Mawlana Bhashani Science and Technology University, Tangail. Protein and fat tests of different samples were conducted in Institute of Food Science and Technology (IFST), Bangladesh Council of Science and Industrial Research (BCSIR), Dhaka.

\subsection{Raw Materials}

Refined wheat flour, flour, holi basil (Ocimum sanctum), Moringa (Moringa oleifera), sugar powder, vegetable oil (soybean), dalda, baking powder, skim milk powder, egg white, iodized salt, and other general ingredients were procured from the local market.

Process of Biscuit Manufacturing: Ingredient was used for preparation of biscuits according to above stated recipe. Sieve the refined wheat flour and other dry ingredients and were mixed together to obtain a uniform blend. Vegetable oil, sugar was mixed together to obtain sweetened shortening cream. Then slowly mixed dry flour was added to shortening cream with addition of water to prepare dough. The dough was prepared by manual kneading of all the dry and liquid ingredients to attain uniformity with desirable visco-elastic characteristics. When dough was ready it was kept for 10-15 minutes as it is and then used for sheeting, sheets were made by rolling balls of dough on wooden platform. These sheets were cut by hand operated metal dye, arranged on olive oil coated tray and were kept for baking. Baking takes place in three successive stages in electric oven. In the beginning structural changes take place due to heating of dough. In second stage greatest loss of moisture take place. In third stage the color of biscuit changes to typical light brown color of finished biscuit. Each lot requires 25-30 minutes at 160 o C for baking.

\subsection{Organoleptic or Sensory Quality Analysis}

The sensory evaluation of prepared herbal biscuits was carried out by a 15 member panel comprising of outdoor diabetic patients from BIRDEM Hospital Dhaka. The panel members were requested in measuring the terms identifying sensory characteristics and in use of the score. Judgments were made through rating products on a five point Hedonic Scale with corresponding descriptive terms ranging from 5 'like extremely' to 1 'dislike extremely'.

\subsection{Biochemical Quality Analysis}

All the samples were subjected to chemical quality assessment. Moisture was determined by oven-drying method, Ash was determined by incineration method, Fat was determined by soxhlet appratus method, Protein by Kjeldahl method and Crude fiber by AOAC - 1995 method [21].

\section{Results and Discussions}

Comparison of Organoleptic or Sensory Qualities of Biscuits: Organoleptic tests of the biscuits depend on its first appearance, color, flavor \& smell, texture, and overall taste of the sample. Table-2 shows the comparison among the biscuits of their organoleptic quality factors.

\subsection{Appearance Acceptability}

Table-2 shows that sample-2 obtained lower score $3.05 \pm 0.16$ for its appearance. Appearances of biscuits depend on appearance of wheat and other raw appearance of ingredients and on processing technique. In the appearance acceptability test, Hedonic scale showed that sample-1 liked very much $(>4)$ by the Judge.

\subsection{Color Acceptability}

Table-2 shows that normal biscuits without incorporation of Tulshi and Moringa leaves (mean is $4.27 \pm 0.70$ ) 
obtained the highest score for its color after that sample-1 obtained second highest score than sample-2 and 3. Color of biscuits depends on the color quality of ingredients.

\subsection{Flavor and Smell Acceptability}

The flavor and smell of the products depends on the volatile constituents of raw material. The flavor mean score were $3.73 \pm 0.80,3.53 \pm 0.70,4.13 \pm 0.56,3.73 \pm 0.65$ of normal, sample-1, sample-2, sample-3 respectively shows in the Table 2. In the flavor and smell acceptability test showed that sample-2like $(>3$ to $<4)$ by the judges and they also like sample-1.

\subsection{Texture Acceptability}

Texture of the biscuits depends mainly upon the rate of development of the dough and the proportion of sugar used.
The wide variation in the quality parameter of biscuits can be attributed to the manufacturing conditions type of raw material used. The mean score of texture were $4.40 \pm 0.74$, $4.20 \pm 0.56,4.05 \pm 0.14,3.25 \pm 0.75$ respectively shows in the Table 2 . Texture of sample-1 was very much liked $(>4)$ by the judges.

\subsection{Overall Taste Acceptability}

Taste is also influenced by the quality of the raw materials used in the processing of biscuits. The mean taste score of biscuits were $4.46 \pm 0.63,4.43 \pm 0.53,4.03 \pm 0.43$, $4.14 \pm 0.57$ respectively shown in the Table- 2 . In taste acceptability test, Hedonic scale showed that the sample-1 biscuit was more acceptable comparing with all quality characteristics by the judge.

Table 3. Nutritive values of different biscuit sample.

\begin{tabular}{|c|c|c|c|c|}
\hline \multirow{2}{*}{ Nutrients } & \multicolumn{4}{|c|}{ Contents per $100 \mathrm{~g}$} \\
\hline & Normal(g) & Sample-1(g) & Sample-2(g) & Sample-3(g) \\
\hline Moisture & 4.8 & 4.6 & 4.5 & 4.7 \\
\hline Protein & 14.7 & 14.8 & 14.6 & 14.9 \\
\hline Fat & 19.5 & 20.1 & 19.9 & 19.3 \\
\hline Ash & 2.1 & 2.2 & 2.3 & 2.4 \\
\hline Crude fiber & 2.3 & 2.9 & 3.5 & 4.1 \\
\hline Carbohydrate & 56.6 & 55.4 & 55.2 & 54.6 \\
\hline Energy (Kcal) & 458 & 460 & 457 & 449 \\
\hline
\end{tabular}

\subsection{Nutritional Quality Assessment}

Table 3 states that, Nutrient contents of normal biscuits that was estimated by using different analytical methods. Per $100 \mathrm{gm}$ (normal biscuits) of product contain 4.8\% moisture, $2.3 \%$ crude fiber, $14.7 \%$ protein, $19.5 \%$ fat, $56.1 \%$ carbohydrate, $2.1 \%$ ash and 458 Kcal Energy. But after incorporating of Tulshi and Moringa leaves the nutritive values were improved. Table-2 also shows the nutrient contents of sample-1 (10g Tulshi $+10 \mathrm{~g}$ Moringa) and the proximate composition of the sample-1 biscuits are $4.6 \%$ moisture, $2.9 \%$ crude fiber, $460 \mathrm{Kcal}$ energy and $14.8 \%$ protein, $20.1 \%$ fat, $55 \%$ carbohydrate, $2.2 \%$ ash. Similarly the nutrient contents of sample-2 (20g Tulshi $+10 \mathrm{~g}$ Moringa) and the proximate composition of the sample- 2 biscuits contain $4.5 \%$ moisture, $3.5 \%$ crude fiber, 457 Kcal energy and $14.6 \%$ protein, $19.9 \%$ fat, $55 \%$ carbohydrate, $2.3 \%$ ash. The nutrient contents of sample-3 (30g Tulshi+30g Moringa) and the proximate composition of the sample- 3 biscuits contain $4.7 \%$ moisture, $4.1 \%$ crude fiber, 449 Kcal energy and $14.9 \%$ protein, $19.3 \%$ fat, $54 \%$ carbohydrate, $2.3 \%$ ash. Above nutritional quality assessment concludes that Sample 1 biscuit is comgtm nparatively better than other sample.

Table 1. Recipe for different biscuit sample.

\begin{tabular}{lllll}
\hline Food Item & Normal(g) & Sample-1(g) & Sample-2(g) & Sample-3(g) \\
\hline Whole wheat flour & 100 & 90 & 80 & 380 \\
Wheat flour & 400 & 390 & 20 & 370 \\
Tulshi Leaves & - & 10 & 20 & 30 \\
Moringa Leaves & - & 10 & 150 & 100 \\
Sugar powder & 150 & 150 & 100 & 100 \\
Vegetable Oil & 100 & 100 & 100 & 100 \\
Dalda & 100 & 100 & 60 & 60 \\
Skim Milk powder & 60 & 60 & 60 & 60 \\
Egg white & 60 & & 60
\end{tabular}


Table 2. Comparison of the different organoleptic quality parameters (Sensory evaluation) of biscuits.

\begin{tabular}{|c|c|c|c|c|}
\hline \multirow{3}{*}{ Quality Parameters } & Normal biscuits & Sample-1 & Sample-2 & Sample-3 \\
\hline & Points & Points & Points & Points \\
\hline & Mean \pm SD & Mean \pm SD & Mean \pm SD & Mean \pm SD \\
\hline Appearance & $4.07 \pm 0.26$ & $4.08 \pm 0.17$ & $3.05 \pm 0.16$ & $3.08 \pm 0.12$ \\
\hline Color & $4.27 \pm 0.70$ & $4.17 \pm 0.05$ & $4.05 \pm 0.40$ & $3.17 \pm 0.57$ \\
\hline Flavor \& Smell & $3.73 \pm 0.80$ & $3.53 \pm 0.70$ & $4.13 \pm 0.56$ & $3.73 \pm 0.65$ \\
\hline Texture & $4.40 \pm 0.74$ & $4.20 \pm 0.56$ & $4.05 \pm 0.14$ & $3.25 \pm 0.75$ \\
\hline Overall taste acceptance & $4.46 \pm 0.63$ & $4.43 \pm 0.53$ & $4.03 \pm 0.43$ & $4.14 \pm 0.57$ \\
\hline
\end{tabular}

\section{Conclusion}

Tulshi and Moringa leaves addition into biscuit formulation had considerable effects on physicochemical and sensory properties of biscuits. It may be concluded from the study that Tulshi and Moringa leaves can be successfully incorporated in wheat flour biscuits up to a level of $1 \%$ to yield biscuits of enhanced nutritional quality with acceptable sensory attributes. Hence, development and utilization of such functional foods will not only improve the nutritional status of the population but also helps those suffering from degenerative diseases. More studies should be conducted to investigate the possibility of using degenerative as an ingredient in other food products in order to increase applications of such value-added food ingredient.

\section{Acknowledgements}

We are thankful to the technical members of the Department of Food Technology and Nutritional Science and to the participant subjects in this study for their all cordial assistance.

\section{References}

[1] James, M., Lattimer and Mark D. H. "Effects of Dietary Fiber and Its Components on Metabolic Health" (2010). Nutrient, 2: 1266-1289.

[2] Dietary fiber, University of California, Berkeley Bancroft Way Berkeley, CA 9472

[3] Jenkins, D.J.A., Wolever, T.M.S., Leeds, A.R., Gassull, M.A. and Haisman, P.J.B. "Dietary fibres, fibre analogues and glucose tolerance: importance of viscosity" (1978). Brit. Med. J. 1:1392-94.

[4] Holt, S., Heading, R.C., Carter, D.C., Prescott, L. F. and Tothill, P. "Effect of gel fiber on gastric emptying and absorption of glucose and paracetamol" (1979). Lancet 1:636-39.

[5] ADA (American Dietetic Association). Position of the American Dietetic Association: "Health implications of dietary fiber" (2008). J. Am. Diet. Assoc. 108: 1716-31.

[6] James, M., Lattimer and Mark D. H. "Effects of Dietary Fiber and Its Components on Metabolic Health" (2010). Nutrient. 2: 1266-1289.

[7] IFIC (International Food Information Council) (2008). Fiber Fact Sheet. Retrieved Nov. 10, 2010.
[8] Geiss L. S., Herman W. H. and Smith P.J. "National Institute of Diabetes and Digestive and Kidney Disease" (1995). NIH Publication No. 95-1468; pp. 233-257.

[9] Report of the Expert Committee on the Diagnosis and Classification of Diabetes Mellitus (1997). Diabetes Care 20: $1183-1197$.

[10] Blackburn, N. A., Redfern, J. S., Jarjis, H. and Holgate, A. M. "The mechanism of action of guar gum in improving glucose tolerance in man" (1984). J. Clin. Sci. 66: 329-36.

[11] Pasha, I., Parveen, S., Salim, U.R. and Nawaz, H. "Baking quality of wheat flour cookies supplemented with fiber from different sources" (2008). Pak. J. Food. Sc. 18:1-4

[12] Maheshwari, R., Rani, B. Yadav, R. K. and Prasad, M. "Usage of Holy Basil for Various Aspects" (2012). Bull. Env. Phar. and Life Sci. 1: 63 - 65.

[13] Shama, S. N. "A mine of medicinal uses: Ocimum sanctum" (2012). Int. J. of Phar. Rev. Res. 2 (2): 69-74.

[14] Kumari, P., Sharma, P. S. and Srivastava M. M. "Biosorption studies on shelled Moringa oleifera Lamarck seed powder: Removal and recovery of arsenic from aqueous system” (2006). Int. J. Miner. Proc. 78:131-139.

[15] Caceres, A., Saravia, A. S., Rizzo, L., Zabala, E. D., Leon and Nave, F. "Pharmacologic properties of Moringa oleifera: screening for antispasmodic, anti-inflammatory and diuretic activity" (1992). J. of Ethnophar. 36(3): 233-237.

[16] Marugandan, S., K. Srinivasan, S. K. Tandon and H. A. Hasan. "Anti-inflammatory and analgesic activity of some medicinal plants" (2001). J. Med. Aromat. Plant. Sci. 22:56-58.

[17] Ples, M. And Howell H., Comparative Effects of Moringa Oleifera Lam. Tea on Normal and Hyperglycemic Patients. E-health Int. J. available at: http://www.researchmoringa.com/uploads/2eHealth_Internat ional_Blood_Sugar.pdf

[18] Kulkarni, S.D. Roasted soybean in cookies. Influence on product quality (1997). J. Food Sci. Technol. 34: 503-505.

[19] Akubor, P. "Functional properties and performance of cowpea/ plantain/ wheat flour blends in biscuits" (2003). Springer. 58 (3):1-8.

[20] Pratima, A. and Yadava, M.C. "Effect of incorporation of liquid dairy by products on chemical characteristics of soyfortified biscuits" (2000). J. of Food Sc. and Tech. 37 (2): $158-61$.

[21] AOAC. Official methods of Analysis of AOAC, International, Washington, DC: Association of Official Analytical Chemist (1990). 16: 1546. 